\title{
Comparing Recommendations to Reality: First Aid Training and Equipment for Amateur Yacht Crews on Ocean Passages
}

\author{
Alison M. Forbes, MB.ChB, Dip. Med. Ed.
}

\begin{abstract}
Introduction - The aim of this study was to establish the first aid skills possessed and equipment carried by sailors participating in the 2018 Atlantic Rally for Cruisers and to compare these with expert recommendations for skills and diagnostic/monitoring equipment to be carried aboard.

Methods-A questionnaire survey was done of 179 boats at Las Palmas, and 88 completed questionnaires were returned. The recommendations were derived from a Delphi study that recruited telemedical providers, first aid trainers, and doctors and nurses with experience in ocean crossing in a small boat. The results were considered with reference to the published literature on accidents and injuries in sailors.

Results-Forty-two percent of boats had crew that had completed no or only $1 \mathrm{~d}$ of first aid training in the previous $5 \mathrm{y}$. Twenty-eight percent said that they had too little first aid training; lack of time was cited most frequently for not doing more training. Twenty-three percent only carried a basic or inshore medical kit. The Delphi study generated a core list of 6 skills and 11 pieces of diagnostic/monitoring equipment that should be available.

Conclusions - When compared, the results of the questionnaire and the Delphi study demonstrated a gap in knowledge/preparation among amateur, oceangoing yacht crews. There is a need for increased education about core first aid skills for sailing out of reach of outside assistance and useful diagnostic/monitoring equipment to have available.
\end{abstract}

Keywords: accidents, education, injuries, sailing

\section{Introduction}

Ocean sailors are very isolated and are required to be selfsufficient. To justify a "Mayday" call for a medical event, a skipper/captain must judge that there is immediate risk to life. ${ }^{1}$ However, most medical events are not life threatening, and in these cases the crew should manage with their own training and resources. On an ocean passage, a moderate-sized yacht may be $10 \mathrm{~d}$ from shoreside medical facilities. A prudent skipper will be trained in first aid and carry some medical equipment.

This study had 2 aims: first, to establish what training courses the designated medic aboard these boats had done, what skills they had learned, and what equipment they carried for medical emergencies; and second, to find

No institutional affiliation (retired)

Corresponding author: Alison M. Forbes, 10 Stevensons Court, 61 East. St, Bridport, Dorset DT6 3LB; e-mail: forbesm@ doctors.org.uk.

Submitted for publication August 2019.

Accepted for publication March 2020. a consensus from experts as to the essential skills needed by amateur ocean sailors and the most important diagnostic/monitoring equipment to be carried. The overall goal was to compare these 2 sets of data and to assess discrepancies between best practice and reality. This will aid future decision making by oceangoing sailors about the training and equipment they might need.

Commercial vessels have very strict rules about the level of first aid provision that must be available aboard ship. These regulations are laid down by the international convention on standards of training, certification, and watch keeping for seafarers $(\mathrm{STCW})^{2}$ and were adopted by the international maritime organization, a branch of the United Nations. They specify the details of a course that must be completed by a crewmember on ships traveling up to $278 \mathrm{~km}$ (173 mi, 150 nautical miles [M]) offshore and a more advanced course for those venturing worldwide. Advanced first aid training was defined as more than $1 \mathrm{~d}$ of training in the last $5 \mathrm{y}$. Likewise, for merchant shipping and fishing vessels, there are regulations derived from European Commission directive 
92/29/EEC, the merchant shipping notice $1768(\mathrm{~m}+\mathrm{f})$ ships' medical stores. ${ }^{3}$ This notice lays out the standard medicine and equipment that must be carried by the designated vessel at varying distances from shore. Category " $A$ " covers those to be carried on ships travelling more than $278 \mathrm{~km}(173 \mathrm{mi}, 150 \mathrm{M})$ offshore. There are no medical regulations for British-flagged noncommercial boats. The training of the crew and the drugs and equipment carried are the sole responsibility of the skipper.

A number of papers have studied the illnesses and injuries that befall amateur sailors, ${ }^{4-11}$ so the likely events are well known. The level of training of amateur boat crews and the medical equipment typically carried are not covered in the literature. This study aims to fill this gap.

\section{Methods}

\section{ETHICS}

A survey of nonvulnerable adults asked about the extent of first aid training they had undergone and the first aid equipment and medicines they were carrying on their boats. There were no questions about the health of the participants. The researcher was not in a position of power/authority over the participants. Yacht crews were at liberty to decline to participate without giving a reason. After giving due consideration to the possibility, it was concluded that there was no likelihood of psychological distress in respondents. The questionnaire had a statement guaranteeing confidentiality and anonymity for the participants and that survey completion would only take a few minutes. The surveys had no identifying marks and cannot be linked to the master copy of participating yachts. The Delphi study asked experts questions on their field of expertise.

The investigation was conducted in 2 phases, a questionnaire and a Delphi study.

\section{QUESTIONNAIRE STUDY}

This aimed to answer the question "To what extent are amateur yacht crews, about to embark on an ocean passage, prepared for medical events on board?"

The estimated number of cruising boats undertaking long voyages is approximately 8000 worldwide at any given time. ${ }^{12}$ A convenience sample of boats about to set off on the Atlantic Rally for Cruisers (ARC) from Las Palmas, Gran Canaria, to Rodney Bay, St. Lucia, was taken. In 2018, there were 179 boats leaving together. The working language of the ARC is English.

The questionnaires were piloted on ocean sailors prior to use to examine clarity of questions and note unusual responses. One questionnaire was given to each boat in its welcome pack when it arrived in Las Palmas for the ARC start. They were then collected a few days before the boat's departure. Eighty-eight completed questionnaires were returned for a response rate of $49 \%$. There were 15 questions covering the number of days of first aid training undertaken and the nature and depth of the courses. Questions were also asked about the first aid equipment carried aboard.

The responses were manually collated and descriptive statistics calculated.

\section{DELPHI STUDY: SETTING, SAMPLE SIZE, AND RECRUITMENT}

The purpose of the Delphi study was to gain expert consensus on the essential advanced first aid skills and necessary diagnostic/monitoring equipment to be carried aboard. Delphi participants were selected from telemedicine providers and first aid trainers to the maritime industry. The trainers taught courses up to and including the STCW courses. A database provided by the Ocean Cruising Club (OCC) was also used. The OCC has an entry requirement of having made a nonstop voyage of at least $1852 \mathrm{~km}(1151 \mathrm{mi}, 1000$ $\mathrm{M})$. Several doctors and nurses who are members can therefore give a credible opinion on the practical skills that are realistic for a nonmedically trained sailor to perform on a small vessel.

The Delphi panel members were chosen to have slightly different perspectives on the essential skills: the telemedical providers on what they hoped the crew could do, the trainers on what was easy to learn and remember, and the OCC doctors and nurses what was feasible to do on a small boat. There is no clear agreement for the optimal Delphi panel size, and various sizes ranging from a minimum of 7 to a maximum of 30 have been suggested. ${ }^{13}$ "Snowball" sampling ${ }^{14}$ was used to generate a list of 5 telemedicine specialists, 4 first aid trainers, and 6 doctor or nurse ocean sailors (practicing or within $5 \mathrm{y}$ of retirement). This generated a list of 15 , which is in the range of 10 to 18 experts and allowed for a $33 \%$ attrition rate, which would still leave 10 to complete the study. ${ }^{15}$ The identified 15 experts were invited to participate, and the Delphi process was explained, including that a maximum of 6 rounds would take place. ${ }^{13}$ The panel was recruited from North America and Europe and participated in 2019.

\section{THE DELPHI PROCESS}

\section{Round 1: "Brainstorming"}

Two open questions were emailed with a request for up to 6 responses for each question. They were as follows: 
1. Excluding those covered by $1 \mathrm{~d}$ elementary first aid courses, what practical medical procedures/skills should be taught to amateur ocean sailors? Assume no medical/ nursing/paramedical training has been undertaken.

2. What medical diagnostic/monitoring equipment should be carried on a small yacht of less than $21.3 \mathrm{~m}$ (70 ft) on an ocean passage, if the vessel is not constrained by commercial regulations?

The second question was limited to diagnostic/monitoring equipment because it was assumed that crews who had advanced first aid skills would take the necessary equipment to use those skills.

Fourteen participants responded, and these replies were collated and categorized. There were 45 skills in response to question 1 and 21 pieces of diagnostic/monitoring equipment derived from question 2.

\section{Round 2: "Verification"}

The collated and categorized responses were then returned to the participants, who were asked to verify that that their own contribution was adequately represented. Fourteen confirmations of verification were received, and 2 corrections were made. Next, the skills and equipment responses for each question were placed in random order using a random number generator.

\section{Round 3: "Narrowing down"}

The participants were asked to select the 10 most important items from the randomized list provided for each question. Twelve participants completed this round. Those items that were selected by $50 \%$ (6) or more of the participants as being in the top 10 most important were taken through to the next round. Six skills and 11 items of diagnostic/monitoring equipment fulfilled this criterion. They were presented to the participants in random order.

\section{Round 4: "Ranking"}

The participants were asked to rank the items for the 2 questions from low to high, where 1 was the most important. Thirteen participants completed this round. A spreadsheet was created, and mean and modal ranks for each skill and equipment item were calculated.

\section{Round 5: "Generating consensus"}

The lists, this time in rank order, were presented again to the participants, with the mean and modal rankings and the participating individual's personal rankings. Comments were also attached from other participants about the skills and equipment. The panel was then asked to re-rank the items in both sections in light of this information. Comparing one's own response with that of the group is thought to help generate consensus. ${ }^{13}$ Ten participants completed this round.

\section{Round 6: "Final round"}

The lists, again in rank order, were returned to the participants, with the mean and modal rankings and the participating individual's personal rankings. More comments were also attached from other participants about the skills and equipment. Again, the panel was asked to re rank their responses. Thirteen participants completed this round.

The stopping rule was applied. Six rounds had been completed.

A final calculation of mean, modal, and median rankings was done, and Kendall's coefficient of concordance for each question was calculated. Interpretation of Kendall's $W$ (p767) ${ }^{16} 0.5$, suggests moderate agreement.

\section{Results}

\section{QUESTIONNAIRE STUDY}

The following is the survey including responses (raw data).

\section{Ocean Sailors' Survey}

Hello! I am Dr Maria Forbes (now retired) and I am an ocean sailor. I would be really glad of your help in answering a few questions on first aid training and medical equipment. I want to know how much first aid or medical training you have had and what medical equipment and stores you will be taking across the Atlantic.

The questions will only take a few minutes. Please note that all responses are anonymous and confidential and will only be used for the purposes of this survey, which aims to improve the safety of ocean sailors. Questions should be answered by the skipper or the crew member responsible for first aid and medical issues (if not the skipper). Please mark boxes with an $X$.

1. What is your role on board, for the Atlantic crossing? $\square$ Skipper/Captain $69(78 \%) \quad \square$ Crew member in charge of medical issues 17 (19\%)

2. Has the skipper/captain undertaken any ocean passages over $1852 \mathrm{~km}(1151 \mathrm{mi}, 1000 \mathrm{M})$ before?

$\square$ Yes $53(60 \%) \quad \square$ No $33(37 \%)$

3. In the last $5 y$, how many days first aid training have you completed?

$\square 0: 11(12 \%) \quad \square 1: 26(30 \%) \quad \square 2$ to $5: 36$
(41\%) $\square 6$ to $10: 8(9 \%) \quad \square 10<: 5(6 \%)$ 
4. Did you do any of the standards of training, certification, and watch keeping for seafarers (STCW) courses, and if so, which?

$\square$ No 65 (74\%) $\quad \square$ Medical first aid aboard ship (4 d)

$10(11 \%) \square$ Medical care aboard ship (5 d) 2 (2\%)

$\square$ Both courses 9 (10\%)

5 . Did you do any other advanced first aid course?

$\square$ Yes (go to $Q .6$ ) 31 (35\%) $\square$ No (go to $Q .7$ ) 57 $(65 \%)$

6. Please describe this other first aid course: (this open question generated 28 free-text answers)

Specific marine first aid course for nonmedically trained (12)

Wilderness first aid training (2)

Bespoke private training (2)

Work-related first aid for medically trained (7)

Work-related first aid for nonmedically trained (4)

Non-marine-, non-work-related first aid course (1)

7. How was the first aid training you did (if any)?

$\square$ Too little (go to $Q .8$ ) 25 (28\%) $\quad \square$ Too much (go to

Q. 9) $0(0 \%) \square$ Just right (go to $Q$. 10) 54 (61\%)

8. Why did you not do more training? (Mark all that apply, then go to $Q$. 10)

$\square$ Lack of time 18 (20\%) $\square$ No suitable course 2 (2\%) $\square$ No suitable venue $3(3 \%) \square$ Cost 4 (5\%) $\square$ Other (please specify) 2 (2\%) "Hope not needed, have telemedical support," "No interest"

9. What was in the training that you thought was unnecessary?"

Although no one answered "too much" to Q7, 2 free answers were given "CPR-not likely to be successful at sea" and "Defibrillator not realistic when days offshore"

10 . Which (if any) of the following medical procedures have you been trained to do? (Mark all that apply)

$\square$ Suturing (stitching) wounds $48(55 \%) \quad \square$ Intramuscular injections $41(47 \%) \square$ Intravenous access 23 (26\%) $\square$ Intubation 17 (19\%) $\square$ Urinary catheterization $17(19 \%) \quad \square$ Rectal infusions 17 (19\%)

11. Approximately what level of medical equipment and supplies do you have on board?

$\square$ Standard off-the-shelf first aid kit (eg, from local pharmacy or chandlery) 9 (10\%) $\square$ Specialist inshore medical kit (eg, including epinephrine/EpiPen, oral antibiotics) $11(12 \%) \square$ Specialist offshore medical kit (eg, as inshore, but including codeine, morphine, injectable antibiotics, splints for fractures) 24 (27\%) $\square$ Specialist ocean medical kit (eg, as offshore, but including suture kit, urine analysis strips, urinary catheters, rectal infusion kit) 15 (17\%) $\square$ Medical kit with all items recommended by World Cruising Club for the ARC $24(27 \%) \square$ Other (please specify) 4 (5\%): 2 stated that they were medical practitioners and had chosen their own kit, and 2 stated that they had added items to a standard kit.

12. Do you carry oxygen?

$\square$ Yes 7 (8\%) $\quad \square$ No 81 (92\%)

13. Do you carry a defibrillator (AED)?

$\square$ Yes 8 (9\%) $\square$ No 80 (91\%) One crew carried both oxygen and a defibrillator

14. What is the highest medical qualification of anyone on board?

$\square$ Doctor $11(12 \%) \quad \square$ Nurse 4 (5\%) $\quad \square$ Paramedic 1 (1\%) $\square$ Advanced first aider $44(50 \%) \quad \square$ First aider $23(26 \%) \quad \square$ None $3(3 \%) \square$ Other (please specify) 1 dentist, 1 Chinese acupuncturist

15 . What is the national flag of your boat?

British 31 (35\%) US 6 (7\%) $\quad$ French 3 (3\%) Others 8 $(9 \%)$

Swedish $7(8 \%) \quad$ Australian $4(5 \%) \quad$ Canadian 2 $(2 \%)$

German $6(7 \%) \quad$ New Zealand $4(5 \%) \quad$ Croatian $2(2 \%)$

Netherlands $6(7 \%)$ Norwegian $4(5 \%) \quad$ Danish $2(2 \%)$

Thank you for your help! I (or another researcher) will collect this questionnaire in Las Palmas; we shall give you the opportunity to seek clarification of the questionnaire or ask us any questions that may occur to you. We may ask 1 or 2 supplementary questions. We hope to publish the results in a medical journal and in the yachting press. Bon Voyage!

\section{DELPHI STUDY}

See Tables 1 and 2 for the collated results from Round 1 and Tables 3 and 4 for the final results of the 2 questions.

\section{Discussion}

Forty-two percent of respondents had no advanced first aid training. The respondent was the skipper or the crew member responsible for first aid and medical issues (if not the skipper). Thus, it is very likely that $42 \%$ of boats participating in the event did not have any crew member with advanced first aid training. Lack of time was most frequently cited as the reason for not doing more training. The full STCW course takes $9 \mathrm{~d}$ in total and covers items that this Delphi study did not consider to be essential, such as rectal infusion and urinary catheterization. Some crews found a suitable intermediate-length course or arranged bespoke training. The other advanced first aid courses taken included courses run by national sailing 
Table 1. Skills collated from round 1 (45 items)

\begin{tabular}{|c|}
\hline Skills \\
\hline Wounds \\
\hline Cleaning of wounds \\
\hline Applying wound closure strips/suture glue/stapling \\
\hline Suturing \\
\hline Use of tube gauze for fingers \\
\hline Management \\
\hline Triage \\
\hline Recognize when to call for help/advice \\
\hline Preparation for evacuation and rescue \\
\hline Medication safety \\
\hline Pain evaluation \\
\hline Pain control \\
\hline Infection control \\
\hline Identification of mental health crisis \\
\hline Stroke recognition \\
\hline Miscellaneous \\
\hline Removal of foreign body on cornea \\
\hline Use of Morgan lens for flushing eyes \\
\hline Drainage of subungual hematoma \\
\hline Incision and drainage of abscess \\
\hline Fish hook removal \\
\hline Defibrillation \\
\hline Treatment of marine envenomation \\
\hline Urinary catheterization \\
\hline Use of stethoscope \\
\hline Multiple uses of safety pins \\
\hline Management of dental emergencies \\
\hline Ear syringing, aural toilette, and use of auroscope \\
\hline Immobilization \\
\hline Basic long bone and finger splinting \\
\hline Reduction of dislocations of finger/shoulder/femur \\
\hline Immobilization of spinal injury \\
\hline Airway \\
\hline Placing an airway in an unconscious patient \\
\hline Advanced airway management \\
\hline Oxygen administration \\
\hline Fluid infusion and bleeding \\
\hline Fluid infusion per rectum \\
\hline Fluid infusion by intraosseous route \\
\hline Hemostatics, tourniquets, and packing \\
\hline Injections \\
\hline Subcutaneous for local anesthesia \\
\hline Intramuscular \\
\hline Intravenous \\
\hline EpiPen-specific technique \\
\hline Assessment \\
\hline Medical history taking \\
\hline Basic physical examination \\
\hline Head injuries, Glasgow Coma Score (GCS) \\
\hline Vital signs \\
\hline Chest pain \\
\hline Burns \\
\hline Trauma \\
\hline
\end{tabular}

organizations and coastguards, some as a requirement for an offshore/ocean sailing skipper's license.

The Delphi panel reached consensus on both questions at a moderate level, ${ }^{16}$ with Kendall's coefficient over 0.5 in both cases, despite having 3 slightly different professional perspectives. The panel rated the diagnostic skills of assessing vital signs and recognizing when to call for help and/or advice as more important than the practical skills (Table 3, skills). Hemostatic techniques, tourniquets, and packing were rated as the third most important advanced skill by the panel, although acute blood loss is not a frequent type of injury. ${ }^{6}$ Skin repair techniques, but not suturing, were important. It is noted that suturing can be difficult under rough conditions. ${ }^{9}$ Hand lacerations composed $8 \%$ of injuries on keelboats. ${ }^{6}$ Fifty-five percent of boat crews claimed to have suturing skills on board. Fractures composed $6 \%$ of injuries, and $25 \%$ of the injuries were rated as severe. ${ }^{6}$ Basic long bone and finger splinting was the fifth most important additional first aid skill according to the Delphi panel. Intramuscular injection skills were considered essential by the Delphi panel, but only $47 \%$ of the boat crews had this skill. The category "A" (ocean) drugs list includes a number of drugs that are given intramuscularly (eg, epinephrine, morphine, antiemetics, and antibiotics). Twenty-three percent of boats carried only either a standard basic or inshore medical kit and therefore would not have been able to treat fractures or severe pain; splints and morphine are only included in the offshore and ocean packs.

The Delphi panel rated satellite telephones or high-frequency radios, which are means of calling for telemedical advice, as the most important piece of equipment to be carried (Table 4, equipment). The rally required all boats to have either high-frequency radio or satellite telephones. It is likely that most oceangoing yachts have this equipment because it is necessary for obtaining weather forecasts and useful for distress calls other than medical emergencies. A stethoscope was indicated for assessing air entry and presence of bowel sounds only. The glucose meter, otoscope, pen torch with blue light, and low-reading thermometer were ranked closely together and low down the priority order. Comments made were that "known diabetics would carry their own glucose meter and one would be very unlikely to newly diagnose a Type 1 diabetic en-route and urinalysis sticks are of more general use." The other items were low ranked because it was stated that otitis externa, corneal abrasions, and hypothermia would be treated symptomatically without precise diagnosis. The pregnancy test was thought useful by some as a differential diagnosis of seasickness and helpful in the diagnosis of ectopic pregnancy as a cause of acute abdominal pain. Of the items listed, blood pressure machines, digital and low-reading 
Table 2. Diagnostic/Monitoring equipment collated from Round 1 (21 items)

\begin{tabular}{ll}
\hline Diagnostic equipment & Monitoring equipment \\
\hline Digital thermometer & Measuring tape \\
Low reading thermometer & Fluorescein and blue light \\
Automated BP machine & Pen torch with blue filter \\
Stethoscope & ECG with ability to transmit \\
Pregnancy test kit & Head torch \\
Malaria test kit & Pulse oximeter \\
Troponin 1 test kit & Magnifying glass/card \\
Urinalysis sticks & Automated external defibrillator (AED) \\
Blood glucose meter & Observation charts \\
Auroscope/Otoscope & Tongue depressors \\
Satellite phone or HF radio enabling remote advice & \\
\hline
\end{tabular}

Table 3. Mean, mode, and median rankings of the 6 skills selected as most important by the Delphi panel

\begin{tabular}{llll}
\hline Skills & Mean rank & Modal rank & Median rank \\
\hline Assessing vital signs & 1.4 & 1 & 1 \\
Recognize when to call for help/advice & 2.5 & 2 & 2 \\
Hemostatic techniques, tourniquets and packing & 3.5 & 3 & 3 \\
Applying wound closure strips/suture glue/stapling & 4.1 & 3 & 4 \\
Basic long bone and finger splinting & 4.6 & 5 & 5 \\
Intramuscular injections & 4.9 & 6 & 6 \\
\hline
\end{tabular}

Kendall's coefficient of concordance $W=0.51$.

thermometers, and stethoscopes are only found in offshore and ocean first aid kits. Twenty boats (23\%) did not carry this level of equipment, having only basic or inshore kits. Urinalysis sticks and pregnancy tests are only in ocean kits. Only 15 boats (17\%) carried an ocean kit. Pulse oximeters, glucose meters, otoscopes, and pen torches with blue lights are not listed on commercial prepacked kits.

An automated external defibrillator was not included on the list of equipment by the panel because of the inability to provide definitive care aboard, yet 8 (9\%) of the ARC boats carried one. These are expensive items, and the money used to purchase them could probably be more usefully spent on more training or cheaper, more useful equipment.

\section{LIMITATIONS}

Known problems with this convenience sample of ocean sailors for the questionnaire include a minimum boat length

Table 4. Mean, mode, and median rankings of the 11 items of diagnostic/monitoring equipment selected as most important by the Delphi panel

\begin{tabular}{llll}
\hline Equipment & Mean rank & Modal rank & Median rank \\
\hline Satellite phone/High-frequency radio & 1.5 & 1 & 1 \\
Blood pressure machine & 3.2 & 3 & 3 \\
Digital thermometer & 3.9 & 2 & 4 \\
Stethoscope & 5.6 & $2 / 3 / 4 / 9$ & 5 \\
Urinalysis sticks & 5.7 & 5 & 5 \\
Pulse oximeter & 6.2 & $6 / 7$ & 6 \\
Glucose meter & 7.2 & $6 / 10$ & 6 \\
Otoscope & 7.3 & 8 & 8 \\
Pen torch and blue light & 7.8 & $8 / 9$ & 8 \\
Low-reading thermometer & 8.1 & 11 & 9 \\
Pregnancy test & 9.7 & 11 & 10 \\
\hline
\end{tabular}

Kendall's coefficient of concordance $W=0.52$.

Where more than one modal rank is listed, equal numbers of respondents chose that rank. 
restriction and a no-solo-sailors rule in the rally. In addition, there is a substantial fee for the support the rally provides. The participants may be more inexperienced sailors who wish for extra logistical support and who like the social aspect of departure and arrival in a group. It is possible that the rally sailors believe in the safety of numbers and are therefore less concerned about first aid because they think that the rally organizers or the other rally participants will come to their aid if they have a problem. Alternatively, the rally participants may be more cautious about ocean crossing and therefore more prepared than average. It is not possible to say from this sample. Less prepared crews may not have returned the survey, so the average preparedness may be less than appears from the survey. It is a possibility, although unlikely, that the designated medic who completed the survey had less training than another crew member on the same boat. These various factors mean that this questionnaire may not be generalizable to amateur ocean sailors who are not taking part in an organized event. The modest $49 \%$ response rate of the ARC participants represents a small sample of the estimated 8000 ocean cruising boats worldwide. The survey was limited in length so as to not inconvenience the participants of the rally. For the Delphi panel, the first aid trainers were all UK based, but the telemedical providers and OCC members were from both North America and Europe.

\section{Conclusions}

Over one-third of boats (42\%) in this sample had no skipper or designated medic with advanced first aid training, and just under a quarter of boats (23\%) carried only a limited first aid kit. Awareness by amateur ocean sailors of the consensus of the Delphi panel and essential medical skills and diagnostic/monitoring equipment may help skippers to select items more rationally.

Acknowledgments: I thank Mr Andrew Bishop, CEO of the World Cruising Club and organizer of the ARC, for his team's help with the distribution of the questionnaire; Dr Alastair Forbes for assisting with the questionnaire collection and proofreading; and all the members of the Delphi panel.

Financial/Material Support: None.

Disclosures: None.

\section{References}

1. Royal Yachting Association. VHF Radio. Eastleigh: Royal Yachting Association; 2001.
2. International Maritime Organisation. International convention on standards of training, certification and watch keeping for seafarers, 1978. Available at: http://www.imo.org/en/ OurWork/HumanElement/TrainingCertification/Pages/ STCW-Convention.aspx. Accessed August 22, 2018.

3. Maritime and Coastguard Agency. Application of the merchant shipping and fishing vessels (medical stores) regulations 1995 (SI 1995/1802) and the merchant shipping and fishing vessels (medical stores) (amendment) regulations 1996 (SI 1996/2821). Available at: https://www.gov.uk/government/ publications/msn-1768-applying-the-ships-medical-storesregulations-1995. Accessed November 28, 2018.

4. Allen JB, De Jong MR. Sailing and sports medicine: a literature review. Br J Sports Med. 2006;40(7):587-93.

5. Luger TJ, Peham D, Mayr B, Grömer G, Raab H, Luger MF. Emergency preparedness and long-distance leisure catamaran sailing. Science and Sports. 2011;26(3):174-8.

6. Nathanson AT, Baird J, Mello M. Sailing injury and illness: results of an online survey. Wilderness Environ Med. 2010;21(4):291-7.

7. Neville VJ, Molloy J, Brooks JHM, Speedy DB, Atkinson G. Epidemiology of injuries and illnesses in America's Cup yacht racing. Br J Sports Med. 2006;40(4):304-12.

8. Neville V, Folland JP. The epidemiology and etiology of injuries in sailing. Sports Med. 2009;39(2):129-45.

9. Price CJS, Spalding TJW, McKenzie C. Patterns of illness and injury encountered in amateur ocean yacht racing: an analysis of the British Telecom round the world yacht race 1996-1997. Br J Sports Med. 2002;36(6):457-62.

10. Rouvillain JL, Mercky F, Lethuillier D. Injuries on offshore cruising sailboats: analysis for means of prevention. $\mathrm{Br} J$ Sports Med. 2008;42(3):202-6.

11. Ryan KM, Nathanson AT, Baird J, Wheelhouse J. Injuries and fatalities on sailboats in the United States 2000-2011: an analysis of US Coast Guard data. Wilderness Environ Med. 2016;27(1):10-8.

12. Cornell J. Where do all the boats go? Global movement of sailing vessels in 2015. [Appendix] Atlantic voyage planning seminar. London: The Cruising Association, London; 2017.

13. Paré G, Cameron AF, Poba-Nzaou P, Templier M. A systematic assessment of rigor in information systems ranking type Delphi studies. Information and Management. 2013;50(5):207-17.

14. Robson C, McCartan K. Real World Research. $4^{\text {th }}$ ed. Chichester, England: John Wiley \& Sons Ltd; 2016:281.

15. Okoli C, Pawlowski SD. The Delphi method as a research tool: an example, design considerations and applications. Information and Management. 2004;42(1):15-29.

16. Schmidt RC. Managing Delphi surveys using nonparametric statistical techniques. Decision Sciences. 1997;28(3): $763-74$. 